\title{
Midwives and Mothers: The Medicalization of Childbirth on a Guatemalan Plantation. By Sheila Cosminsky. 2016. University of Texas Press, Austin. 303 pp.
}

\author{
Amanda M. Thiel ${ }^{1 *}$ and Marsha B. Quinlan ${ }^{1}$ \\ ${ }^{1}$ Department of Anthropology, Washington State University, Pullman, USA. \\ *amanda.thiel@wsu.edu \\ Received February 13, 2018 \\ OPEN ӘACCESS \\ Accepted March 11, 2019 \\ Published April 17, 2019 \\ DOI 10.14237/ebl.10.1.2019.1264 \\ Copyright (c) 2019 by the author(s); licensee Society of Ethnobiology. This is an open-access article distributed under the terms of the Creative Commons \\ Attribution-NonCommercial 4.0 International Public License (https://creativecommons.org/licenses/by-nc/4.0), which permits non-commercial use, distribution, \\ and reproduction in any medium, provided the original author and source are credited.
}

Drawing on four decades of research, medical anthropologist Sheila Cosminsky (Professor Emerita of Rutgers University, Camden, NJ) distills careerlong research into a comprehensive monograph on Guatemalan midwifery. Midwives and Mothers journeys over time to describe changes in midwifery practice on a mixed Maya-Ladino plantation (population 690 in 1970, 313 in 2010) on Guatemala's Pacific coast. The ethnography is positivist, reflexive, ecological, and critical. It compiles and contextualizes local medical ethnobotany including ethno-obstetrics, as the local midwifery tradition spans into family health beyond the Western obstetric realm of pre- and perinatal maternal care. The ethnography draws on medical anthropology, ethnobiology, political ecology, and gender studies to show the changing role of midwives in cultural contexts in which traditional medical practices increasingly interface with biomedical ones.

The process of medicalization is the central theme that Cosminsky builds. She points to the contested power between (1) biomedical clinicians and practices and (2) midwives and midwifery. Readers gain a clear understanding of the culturalhistorical foundations of the dynamics between the medical worldview of traditional Guatemalan midwifery compared to local applications of Western biomedicine. Cosminsky contributes her immense stores of ethnography of traditional treatmentsmostly ethnobotanical — that she documents partly from "concern for midwives" as Guatemala experiences "gradual loss of midwifery knowledge" (p. ix). Accordingly, this book will be useful to interdisciplinary audiences, including ethnobiologists, anthropologists, reproductive health specialists, Latin Americanists, those in gender studies, international development, and Guatemalan and Maya lay people and traditional healers seeking affirmation and documentation of this ethnomedical heritage.

Cosminsky defines medicalization as the process by which biomedicine gains dominance over traditional ethnomedical practice. The book then outlines the levels at which medicalization affects Guatemalan midwifery practice. The author neither denies biomedical benefits nor endorses all midwifery practices. Rather, she teases apart complex issues of power and control to illustrate, with ample concrete examples, the effect of medicalization on midwifery practice in Guatemala. For instance, first-time mothers must give birth in hospitals, and midwives are legally barred from assisting with births at home.

Cosminsky weaves compelling ethnoecological and ethnobotanical information alongside the main themes of medical anthropology and midwifery. In Chapter 2, she shows the direct interrelationship of social and ecological characteristics of finca (plantation) life across four decades, from its basis in unequal land distribution to specific notes on subsistence and sugar and coffee cash-crop production systems. For example, the author highlights the changing role of women in subsistence, as coffee harvesting and pig raising-historically women's activities that contributed to female 
autonomy in a patriarchal society—are not presently a viable income option on the plantation. This shift results in "not only the loss of money but also the loss of community and agency" that differentially hurts women due to economic and gender matters on the finca (p. 48).

Further, Cosminsky's approach bridges ethnobotany with other disciplines by describing and contrasting the roles and activities of two midwives, Doña María and her daughter, Siriaca. For example, Doña María provides new mothers with a postpartum bath, using humorally hot herbs. In the subsequent generation of midwives, Siriaca also administers baths but allows women to choose whether they want herbs and a hot or warm bath. These practical changes are symbolic of the changing midwife role, and illustrate a cultural compromise- a midwife who allows choices of herbs and temperatures - which "undermines the cultural logic of the hot-cold principle and the authoritative knowledge of the midwife" (p. 171). Medicalization is changing midwifery's functions and role, and Cosminsky makes this clear amid rich ethnomedical and ethnobotanical descriptions.

One of Mothers and Midwives' greatest achievements is the clear characterization of the differences between the ethnomedical and biomedical models. Midwifery serves the entire reproductive cycle, from prenatal and perinatal, to postnatal care. The midwife supports the woman and her family socially, spiritually, and physically. In Guatemalan biomedicine (as elsewhere), doctors' and nurses' roles form a relational hierarchy, with midwives below biomedical personnel, and pregnant women below that. Consideration for social dynamics in the woman's family or community and their effect on her pregnancy experience, and for associated financial strain, is absent from the biomedical model. Physicians are almost always men with little regard for cultural modesty surrounding the shame of female genitalia exposure within the patients' ethnomedical model. Biomedical practice provides prenatal and delivery care, while largely neglecting postpartum.
Clinicians make frequent use of advanced technologies and interventions, focus on disease treatment rather than prevention, violate hot-cold humoral principles, and caution against using herbs, the latter often with contradictory rationale about herbs' effectiveness. The differences between biomedical and midwifery practice are clearly impacting women's health care in rural Guatemala.

Another achievement of the book is its rich description of various elements of midwifery practice, from lifestyle prescriptions and ethnoanatomical disease etiology to treatment of spiritual, social, and physical issues affecting the woman and infant. Appendices itemize specific illnesses and ethnobotanical treatments with a comprehensive catalogue of plants. Cosminsky lists these plants according to local common names, scientific names, and uses. In email correspondence with Dr. Cosminsky, we learned of the challenges she underwent in the documentation and deposit of botanical voucher specimens. After losing her first plant press-gifted to her by Dr. Richard Schultes-in a NYC taxi on her way home from fieldwork, she persevered to re-collect botanical vouchers on subsequent trips to Guatemala, and deposited them at the Field Museum in Chicago. The documentation of these practical elements of midwifery and ethnobotany supports the author's aim to capture knowledge before it is lost.

In her closing remarks, Cosminsky admits feeling "a small amount of optimism" about the future of midwives in Guatemala and hopes their knowledge and practices will survive to form part of "a more pluralistic and holistic reproductive health system" (p. 248). Midwives and Mothers brings to light the issues inherent in the medicalization of traditional midwifery practice and embodies an ethnoecological approach to the study of culture change. The book may well empower the next generation of social scientists, medical personnel, and policy makers to encourage more holistic and pluralistic reproductive healthcare in Guatemala, and beyond. 